\title{
BACK RADIATION SUPPRESSION IN MODIFIED APERTURE COUPLED MICROSTRIP ANTENNA BY USING PATCHES UNDER THE SUBSTRATE
}

Richa Sharma, Ms. Amanpreet Kaur, Dr. Rajesh Khanna

M.E., Student, ECED, Thapar University, India richa102030@gmail.com

Assistant Professor ECED, Thapar University, India

Amanpreet.kaur@thapar.edu

Professor, Thapar University,India

\section{ABSTRACT}

rkhanna@thapar.edu

A microstrip slot antenna for C Band has been proposed with compact structure and suppressed back radiation. In this paper, the feeding technique used is aperture coupling with a modification that patches and the feed line are positioned below the substrate and the slot is etched above the substrate. The position of the patches along the slot axis is kept at the negative peak of the standing wave distributions to generate the voltage null on the slot line so as to have a $180^{\circ}$ phase shift in the centre of the patch hence achieving better front to back ratio. Also the gain of $6.774 \mathrm{~dB}$ is achieved in this design. The results are validated by simulation measurements.

\section{Keywords}

Back radiation, directivity, gain, microstrip slot antenna, patch.

\section{Academic Discipline And Sub-Disciplines}

Engineering, Antenna Designs, Wireless Communication.

\section{SUBJECT CLASSIFICATION}

Antenna and Wave Propagation, Microstrip Antennas.

\section{TYPE (METHOD/APPROACH)}

Computer Simulation Technology (CST) 2010 Version.

\section{Council for Innovative Research}

\author{
Peer Review Research Publishing System
}

\section{Journal: INTERNATIONAL JOURNAL OF COMPUTERS \& TECHNOLOGY}

Vol 6, No 3 


\section{INTRODUCTION}

Microwave slot antennas have broad interest in military and commercial applications mainly due to the low profile, low cost as well as being simple to manufacture. Moreover, the slot antennas are quite easily incorporated with planar and non planar surfaces and have more degrees of freedom than a conventional design[1]-[3]. In spite of these advantages, it has the main disadvantage of back radiation, which limits its use in mobile communication. This back lobe is undesired because it shows power loss. It increases SAR (Specific Absorption Rate) for the mobile users [4].

Several methods have been proposed to suppress the back lobe, such as by using array topology [5], a tapered-loaded antenna [6] and a 2 wavelength Microwave Leaky Wave Antenna with coaxial probe coupled patch antenna arrays [7]. In addition, these methods also supported parallel plate modes, thus producing undesired radiation.

To solve such problems, a slot antenna with new aperture coupling design is proposed in this paper. The proposed design includes the slot etched on the substrate and the patches and the feed line are employed on the opposite side of the substrate. The purpose of employing the patches beneath the substrate layer is to reduce the radiation into the half space that they occupy and to increase the radiation in the other half space. Also, this design is compact, since it includes a single substrate layer as compared to conventional aperture coupled antennas.

The design is simulated using CST (Computer Simulation Technology) and the return loss, radiation pattern, gain and directivity are measured. In this paper, we will first study a simple slot antenna without patches under the substrate. This simple slot antenna shows the bidirectional nature of the antenna in the absence of the patch. Next, we will study the design, operation mechanism and simulation results of our proposed antenna.

\section{ANTENNA DESIGN AND OPERATION MECHANISM}

\subsection{Antenna Structure Without Patch}

The figure below shows the Fig. 1 (top view) and Fig. 2 (bottom view) view of the cell structure of a simple aperture coupled microstrip slot antenna. The design is a simple slot antenna with $125 \times 130 \mathrm{~mm}^{2}$ substrate layer with of Rogers RO4232 dielectric material with dielectric constant 3.2 and a slot is cut into the ground of this design which rests on the substrate layer. The microstrip feed line is on the opposite side of the slot and its width is set for $50 \Omega$ characteristic impedance.

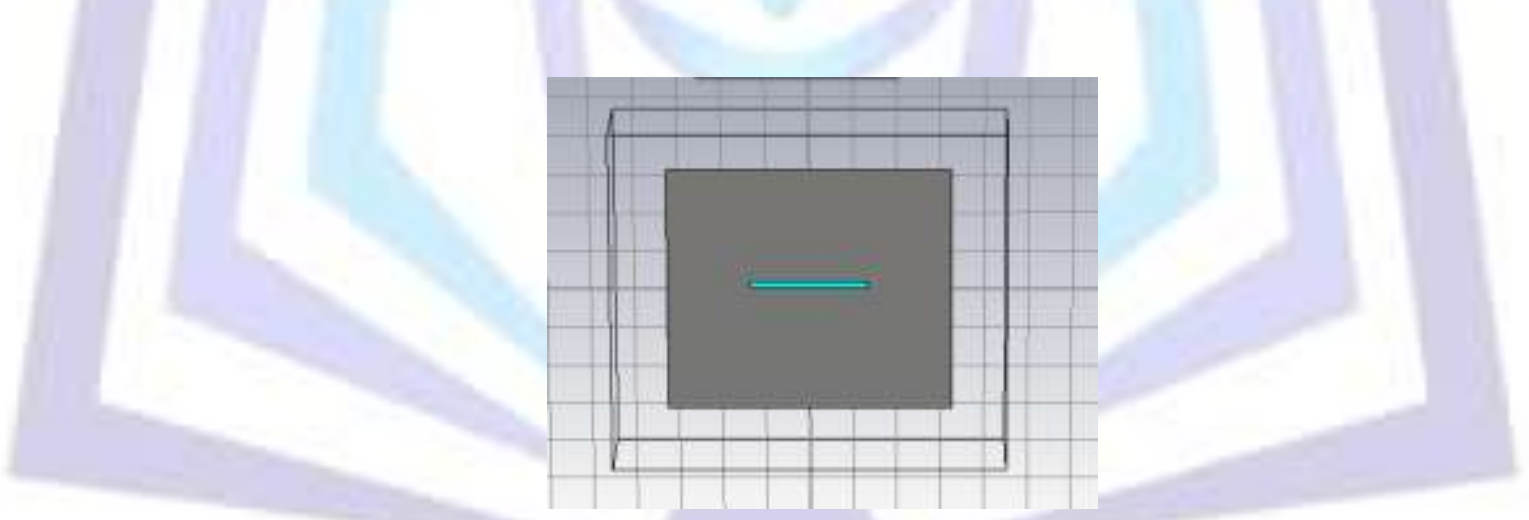

Figure 1Top view geometry of the slot antenna

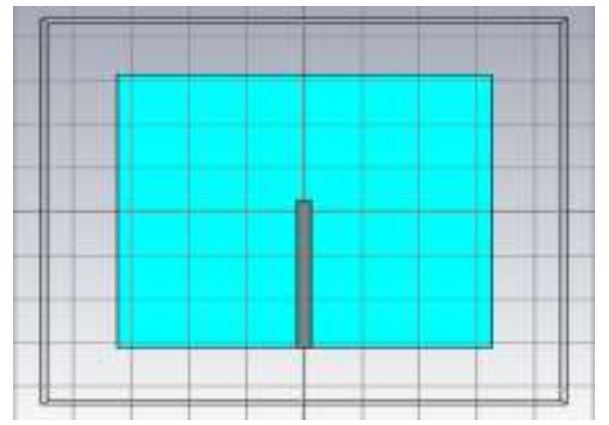

Figure 2 Bottom view geometry of the slot antenna 
The slot in the above design is incorporated to radiate bidirectionally. The $S 11$ parameter and the E field pattern are shown in Fig. 3 and Fig. 4 below

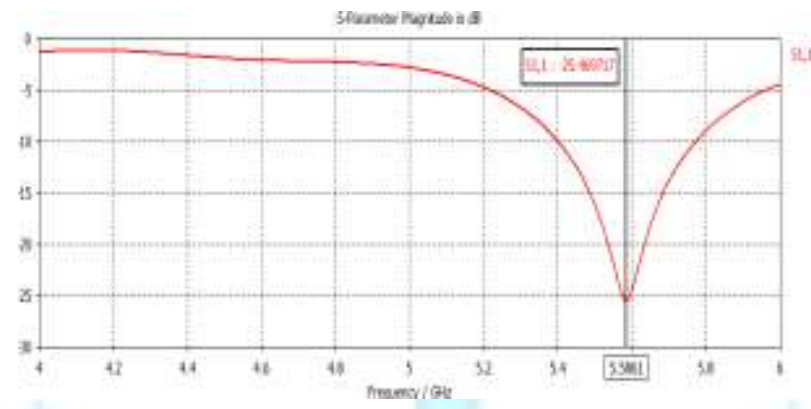

Figure 3 S11 parameter of the slot antenna

E-Field $(r=1 m)$ Abs (Phi=90)

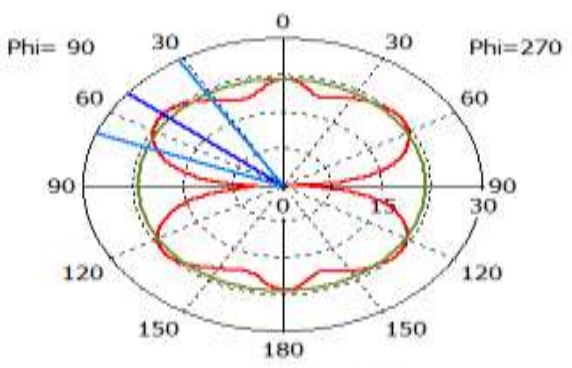

Theta / Degree vs. dBV/m

Figure 4 E Field pattern

The $\mathrm{S} 11$ parameter is $-25.469 \mathrm{~dB}$ and the antenna resonates at $5.57 \mathrm{GHz}$. The $\mathrm{E}$ field pattern shows the bidirectional radiation distribution which is due to the alternating standing wave distribution along the slot axis which reverses over a half wavelength[8]. Since the field is distributed towards both sides, the power density of the antenna hence becomes low.

\subsection{Antenna Structure With Patch}

This is the proposed slot antenna in which there are two slots above the substrate and the patches are under the substrate. The idea of placing patches under the substrate is that the slot electric field perpendicular to the slot length appears to have a standing wave distribution with positive and negative nodes along its axis. The direction of this electric field is reversed after propagating over a half wavelength. Hence, by sliding the patch toward or away from the center of the slot, we can adjust the phase of the patch $180^{\circ}$ by coupling it to the negative voltage node or the positive voltage node on the slot line [9]. The proposed antenna is simulated for different displacements of the patch position and their corresponding field patterns are also studied for better front to back ratio. The geometry of the proposed structure is as follows. 


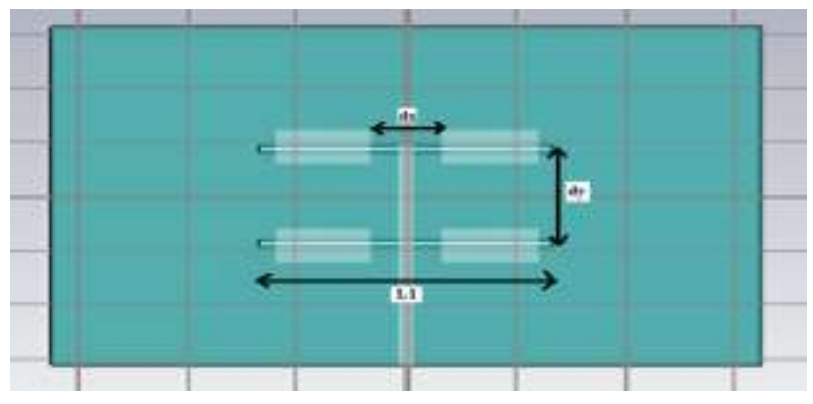

Fig5. Geometry of the proposed antenna

\subsubsection{Design And Simulation Results}

The configuration of the antenna is shown in the figure below. In this paper the antenna is expected to operate in $4.0 \mathrm{Ghz}$ to $5.0 \mathrm{Ghz}$ band. The slots are cut on the ground plane of $125 \times 130 \mathrm{~mm}^{2}$. The effective dielectric constant of the substrate is calculated by using equation (1). After calculating effective dielectric constant, the guided wavelength $\left(\lambda_{g}\right)$ is calculated by using equation (2) and the length and width of slot is given by $L_{1}$ and $W_{1}$ in the Table. The thickness of substrate layer is $h$ $\mathrm{mm}$. The distance $d y=29 \mathrm{~mm}$. The length of the slot is calculated by using equation (3). The remaining dimensions of the antenna are calculated using [10] and are given in the Table 1.

$\varepsilon_{\mathrm{reff}}=\frac{\varepsilon y+1}{2}+\frac{\varepsilon y-1}{2}\left[1+12 \frac{\hbar}{W}\right]^{-1 / 2}$

$\lambda_{\mathrm{g}}=\lambda / \sqrt{\text { ereff }}$

$\mathrm{L}_{1=} \frac{\mathrm{c}}{2 \mathrm{fo} v(\mathrm{areff})}$

Where $\mathrm{c}=3 \mathrm{X} 10^{8} \mathrm{~m} / \mathrm{sec}$
Table 1 Dimensions of antenna:

\begin{tabular}{|l|l|}
\hline Dimensions & Value \\
\hline Substrate height $(\mathrm{h})$ & $1 \mathrm{~mm}$ \\
\hline $\begin{array}{l}\text { Dielectric constant of } \\
\text { substrate } \varepsilon_{\mathrm{r}}\end{array}$ & 3.2 \\
\hline Length of slot $\left(\mathrm{L}_{1}\right)$ & $54 \mathrm{~mm}$ \\
\hline Width of slot $\left(\mathrm{W}_{1}\right)$ & $2 \mathrm{~mm}$ \\
\hline Length of patch $(\mathrm{L})$ & $17.5 \mathrm{~mm}$ \\
\hline Width of patch $(\mathrm{W})$ & $17.5 \mathrm{~mm}$ \\
\hline
\end{tabular}




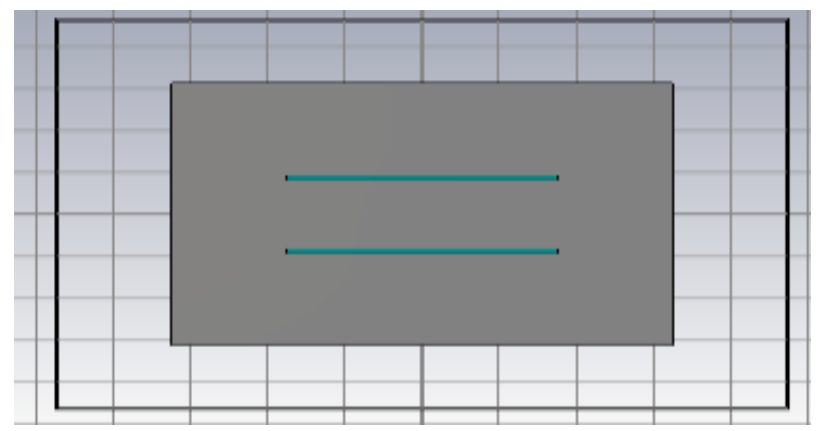

Figure 6 Top View of the proposed antenna

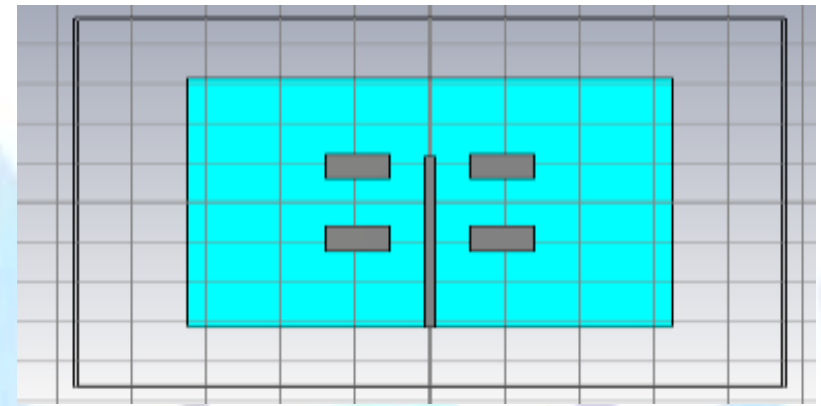

Figure 7 Bottom view of the proposed antenna

According to the operating mechanism described above, the spacing ' $d x$ ' between the two patches is very significant in affecting the antenna performance. Therefore, the antenna structure is simulated for different values of $d x$ and at those values of $\mathrm{dx}$ the return loss, gain, E field pattern and directivity are compared.

\subsubsection{Effect of Spacing ( $d x)$}

Since the effective length of the slot with the partly covered patches will be different from that without patches, the distance of the patches from the center of the slot is chosen to be $1 / 8$ to $1 / 2$ wavelength in the substrate [11]. This range allows the patches to cover the positive or the negative standing wave nodes when they move toward or away from the center of the slot. The antenna is simulated for four values of the $\mathrm{dx}$ spacing: $9,13,17$ and 21 .

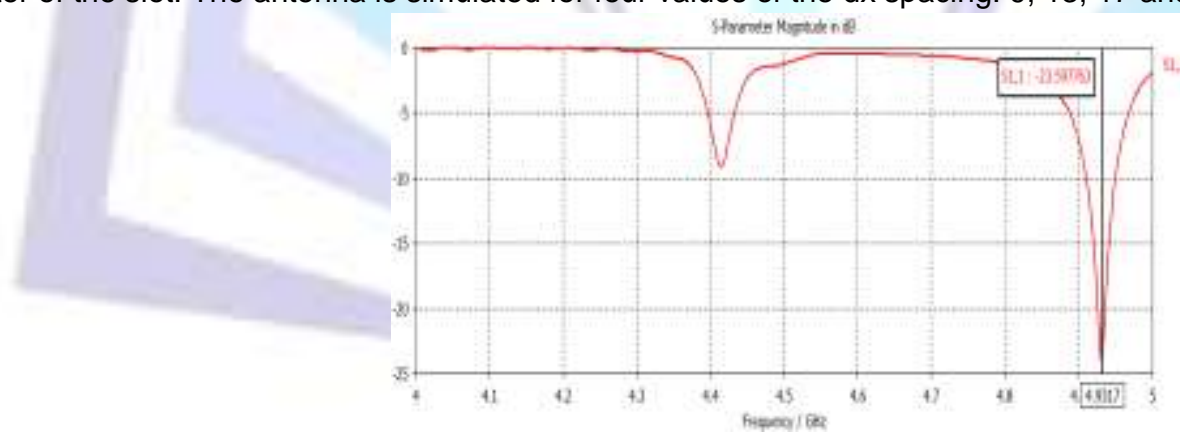

(a)

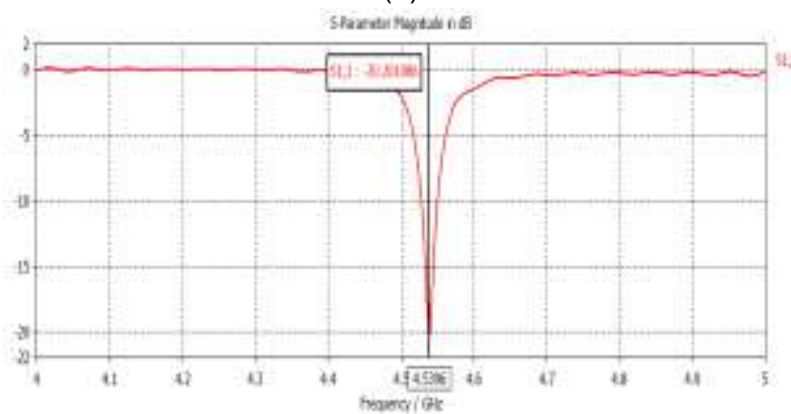

(b) 


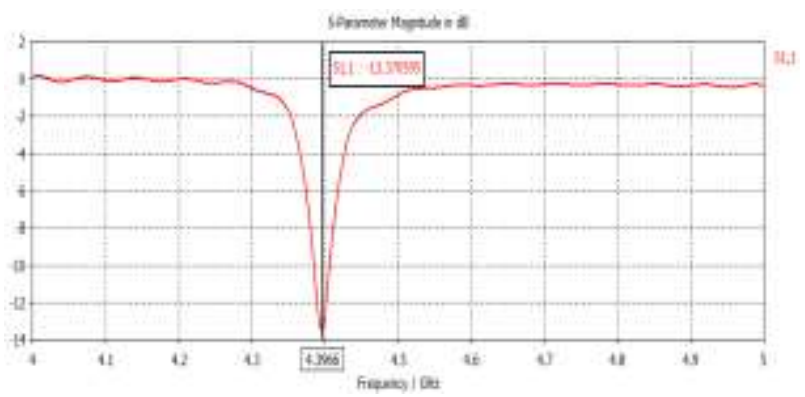

(c)

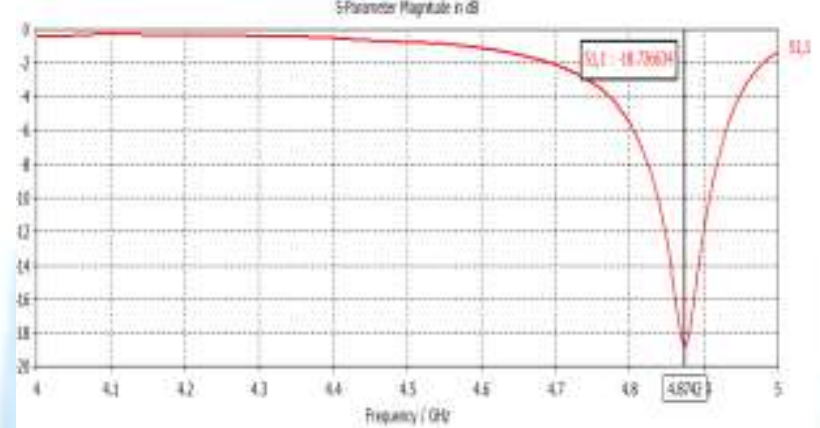

(d)

Figure $8 \mathrm{~S} 11$ parameter for $\mathrm{dx}=9,13,17$ and $21 \mathrm{~mm}$ in (a),(b),(c),(d) respectively

The $\mathrm{S} 11$ parameter for the different spacing between the patch has been simulated. The resonant frequency for $\mathrm{dx}=9 \mathrm{~mm}$ is $4.93 \mathrm{GHz}$, for $\mathrm{dx}=13 \mathrm{~mm}$ is $4.53 \mathrm{GHz}$, for $\mathrm{dx}=17 \mathrm{~mm}$ is $4.39 \mathrm{GHz}$ and for $\mathrm{dx}=21 \mathrm{~mm}$ is $4.87 \mathrm{GHz}$ The resonant frequency is shifted to the left as the distance between the patches increases except for $d x=19 \mathrm{~mm}$ where the frequency starts shifting to the right. Thus, the resonant frequency decreases with increase in the distance between the patches up to a particular displacement of the patch. Beyond that displacement, it again increases. The $E$ field patterns for different patch spacings are as follows.

E-field $(r=1 \mathrm{~m})$ Abs (Phi=90)

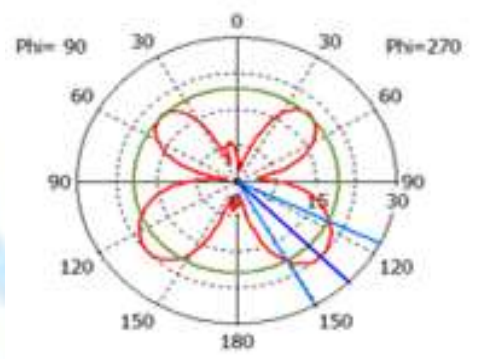

Theta/ Degee ns. dev/m

(a)

E-Fela( $r=1 \mathrm{~m})$ Abs $(\mathrm{Ph}=90$ )

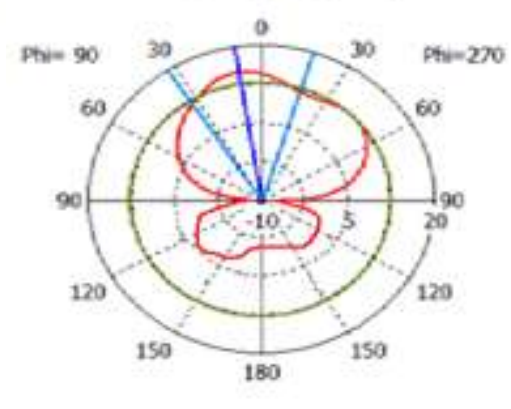

Theta / Degree vs. dBV/m

(b) 


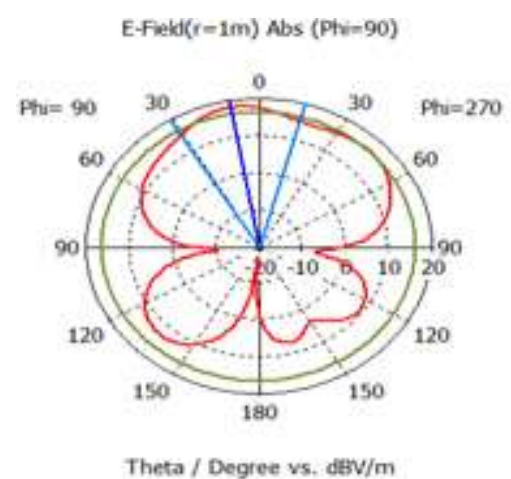

(c)

E-Feld $(r-1 \mathrm{~m})$ Abs (Phi $=90)$

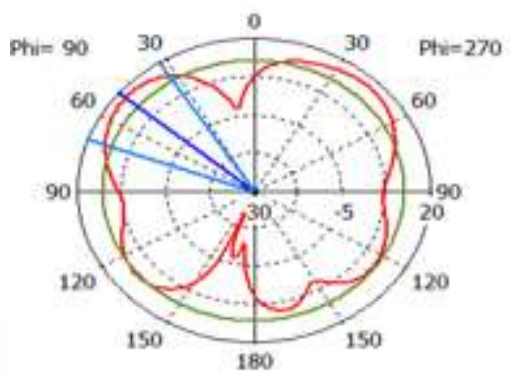

Theta / Degree vs: dBvim

(d)

Figure $9 \mathrm{E}$ field pattern for $\mathrm{dx}=9,13,17$ and $21 \mathrm{~mm}$ in $(\mathrm{a}),(\mathrm{b}),(\mathrm{c}),(\mathrm{d})$ respectively

The electric field pattern for the different displacements of the patch shows a better front radiation at $\mathrm{dx}=13 \mathrm{~mm}$ as shown in (b) in fig. 9. The back radiation is suppressed due to the reason that the effective length of the patch is about half wavelength, it causes voltage null movement in the slot as it moves along the axis of the slot as compared to (a), (c) and (d) in fig. 9 where there are significant side lobes and the back lobe.

Table 2 Comparison of result parameters at different patch displacements

Table 2 shows the comparison of various result parameters for the different patch displacements. The gain is $6.774 \mathrm{~dB}$ and the directivity is $6.255 \mathrm{dBi}$ for $\mathrm{dx}=12 \mathrm{~mm}$ whereas it is less for the other three cases. Also, the coupling is also better at $d x=13 \mathrm{~mm}$ as compared to $d x=17$ and $21 \mathrm{~mm}$. Thus, $d x=12 \mathrm{~mm}$ is the point of voltage null in the slot where the back lobe suppresses to a significant point, hence giving good simulation results.

\section{CONCLUSION}

The back radiation is successfully suppressed in a microstrip slot antenna with modified aperture coupling by varying the patch distance within $1 / 8$ to $1 / 2$ of the wavelength from the centre of the slot. The design of this work has given good results in term of return loss, gain and directivity. This design is very useful for the mobile communication where the back radiation from the cell phone is not desired. This design is also compact in size. However, the proposed design has the simple structure and it can be constructed with a lower cost. 


\section{ACKNOWLEDGMENTS}

We are grateful to the referees for their valuable comments. We also acknowledge the CST software with the help of which we have deduced all the required results and the Thapar University for providing all the resourses for the study and research work.

\section{REFERENCES}

[1] Y. Yashimura, "A microstrip slot antenna", IEEE Trans. Antennas Propag., AP-29, 2-24,1981

[2] R. Garg, P. Bhartia, I. Bahl and A. Ittipiboon, Microstrip antenna design handbook. Norwood, MA: Artech House, 2001

[3] S. K. Sharma, N. Jacob and L. Shafai , "Low profile wide band slot antenna for wireless communications", in Proc. IEEE AP-S Int. Symp., 2002, 390-393

[4] Q. Balzano, O. Garav and T. J. Manning, "Electromagnetic energy exposure of simulated users of portable cellular phone", IEEE Trans. Veh. Technol., 44( 3),390-403, 1995.

[5] C.J. Wang, C.F. Jou, J.J. Wu and S.T. Peng, "Radiation characteristics of active frequency-scanning leaky mode antenna arrays", IEICE Trans. Electron,E82-C,1223-1228,1999.

[6] Ying-Chou Shih, Shing-Kwang Chen, Cheng-Chi Hu and C.F Jou, "Active feedback microstrip leaky wave antennasynthesizer design with suppressed back lobe radiation”, Electronic Letters, 35, 513-514,1999.

[7] I-Yu Chen, Chien-Jen Wang, Hua-Lin Guan and Christina F. Jou, "Studies of suppression of the reflected wave and beam-scanning features of the antenna arrays", IEEE Trans AP (53) 7, 2220-2225, 2005.

[8] Qinjiang Rao, Tayeb A. Denidni and Ronald H. Johnston, "A New Aperture Coupled Microstrip Slot Antenna IEEE Transactions on Antennas and Propagation",53(9), 2818-2826, 2005

[9] Q. rao and R. H. Johnston, "Modified aperture coupled microstrip antenna", IEEE Trans. Antennas Propag.,52, (12),3397-3401,2004.

[10] C. A Balanis, Antenna Theory, $3^{\text {rd }}$ edition, John wiley \& sons, Hoboken, NJ,2005

[11] T. A. Denidni and Q. Rao, "Design of single layer broadband slot antennas", Electron Lett, 40, 460-461, 2004.

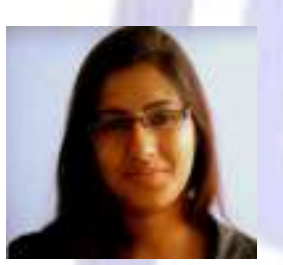

Richa Sharma is pursuing Masters of Engineering degree in Electronics and Communication Engineering from Thapar University. She has received her bachelor degree form Punjab Technical University, Jalandhar (India) in 2009. From 2009-2010 she was a lecturerin Electronics andCommunication department in Lovely Professional Un iversity and from 2010-2011 she was a lecturerin Electronics andCommunication department I Punjab Technical University.

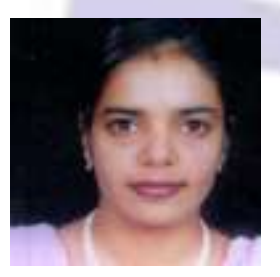

Ms. Amanpreet Kaur is currently working as Assistant Professor in ECE dept at Thapar University. She has received her B.E. degree from Jammu University in 2004 and her M.E. degree from Thapar University, Patiala (India) in 2006 and she is pursuing her Ph.D from Thapar University.

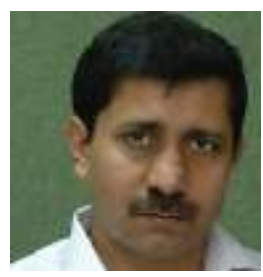

Dr. Rajesh Khanna is currently working as Professor in Thapar Univesity. He has done BSc (Electronics and Communication Engg) from Kurukshetra University (Haryana) and ME in Electrical Communication Engg from IISc Bangalore and PhD from Thapar University, Patiala. His current research interests includes Antenna Design for heterogeneous networks and MIMO Systems. He has authored more than 32 papers in referred journals and conferences. 